\title{
The paradoxical role of urinary macromolecules in the aggregation of calcium oxalate: a further plea to increase diuresis in stone metaphylaxis
}

\author{
J. M. Baumann ${ }^{1} \cdot$ B. Affolter ${ }^{1}$
}

Received: 9 December 2015 / Accepted: 8 February 2016 / Published online: 26 February 2016

(C) The Author(s) 2016. This article is published with open access at Springerlink.com

\begin{abstract}
This study was designed to get information on aggregation (AGN) of urinary calcium oxalate crystals $(\mathrm{CaOx})$ which seems to occur in stone formation despite a protecting coat of urinary macromolecules (UMs). $\mathrm{CaOx}$ crystallization was directly produced in urine, control and albumin solution by Ox titration and was spectrophotometrically followed. A rapid decrease of optical density indicating AGN was absent in 14 of 15 freshly voided urines of 5 healthy controls. However, in the presence of UM-coated hydroxyapatite all urines with relative high sodium concentration, being an indicator of concentrated urine, showed a pronounced AGN which was abolished when these urines were diluted. Albumin relatively found to be an inhibitor of AGN showed after temporary adsorption on Ca Phosphate $(\mathrm{CaP})$ massive self-AGN and changed to a promoter of $\mathrm{CaOx}$ AGN. Self-AGN after adsorption on surfaces especially of $\mathrm{CaP}$, being an important compound of Randall's plaques, can thus explain this paradoxical behavior of UMs. Aggregated UMs probably bridge zones of electrostatic repulsion between UM-coated crystals with identical electrical surface charge. These zones extend by urine dilution which decreases ionic strength. Diminution of urinary concentration by increasing diuresis seems, therefore, to be important in stone metaphylaxis.
\end{abstract}

Keywords Nephrolithiasis - Calcium oxalate aggregation · Albumin · Urinary macromolecules $\cdot$ Selfaggregation

J. M. Baumann

johannes.denise.baumann@bluewin.ch

1 Stone Research Center Viollier, Biel, Switzerland

\section{Introduction}

Overgrowth of interstitial apatite plaques, so-called Randall's plaques (RPs) or renal tubular crystal deposits by calcium oxalate $(\mathrm{CaOx})$ seems to be important pathways in Ca nephrolithiasis [1-4]. RPs start their formation at the interior of the papillary tissue, initially without any contact with urine. Hydroxyapatite (HAP) calcification is induced by organic debris resulting from tissue injury. Later, when HAP deposits cross the epithelial monolayer that covers the papilla and enter in contact with urine, the apposition of $\mathrm{CaOx}$ crystals can occur. Large crystal aggregates being retained in collecting ducts and protruding out to papillary surfaces seem to be another starting point for stone formation. An initially fixed growth on such deposits or RPs allows stones to get a critical size where they cannot be washed out anymore from the kidney by the urine flow. Scanning electron microscopy of RPs mainly showed primary $\mathrm{CaOx}$ aggregates without direct contact to HAP particles and thus without an evidence for heterogenous nucleation of $\mathrm{CaOx}$ by HAP. Therefore, stone growth mainly seems to be based on crystal aggregation (AGN) on RPs, intratubular crystal plugs or preexisting stones during crystalluria $[5,6]$. Since transit time of urine in the upper urinary tract is only in the order of a dozen of minutes, AGN has to occur very rapidly. Like in every biological fluid, urinary crystals are always coated by urinary macromolecules (UMs) [7]. UMs consist of a large group of proteins and some glycosaminoglycans [8]. The number of UMs isolated in urine is steadily increasing. From HAP precipitated in urine of healthy controls 45 , and from brushite 77 different proteins were extracted [9]. The role of these proteins in stone formation is far from being clear. However, coating of crystals by UMs seems to prevent or at least retard AGN often beyond urinary transit time through the kidney [10]. 
This may explain why stone incidence and recurrence are less frequent than it could be expected from the widespread occurrence of RPs and crystalluria.

This paper tries to bring further light on crystal AGN in urine and the overgrowth of RPs or intra-tubular crystal deposits by $\mathrm{CaOx}$, mechanisms still being poorly understood. To this purpose $\mathrm{AGN}$ of $\mathrm{CaOx}$ was measured in urine after rapid Ox titration in the presence and the absence of UM-coated HAP crystals. Since in previous work UMs showed some instability with a tendency to self-AGN [11], freshly voided spot urine was used having spent only a short time in the urinary tract. To mimic the influence of an increased diuresis, crystallization tests were repeated with diluted urine. Tests were also performed with UMs isolated from urine by $\mathrm{Ca}$ phosphate precipitation and consecutive dissolution of the precipitate. Furthermore, results were compared to experiments performed with albumin, being an important compound of crystal coats and stone matrix [8].

\section{Materials and methods}

\section{Special equipment}

Ionic $\mathrm{Ca}$ and $\mathrm{Na}$ concentrations were measured by ionselective electrodes (AVL List $\mathrm{GmbH}$ ). Light absorption or optical density (OD), respectively, in urine and solutions was measured at $620 \mathrm{~nm}$ and $37^{\circ} \mathrm{C}$ in a Perkin Elmer spectrophotometer 550S (Perkin Elmer, Rotkreuz, Switzerland). OD was recorded with a DI-194RS serial port data recording module (DataQ Instruments, Ohio, USA) and for further calculation transferred to an Excel sheet. Particle size distribution was determined by a Malvern Zetasizer Nano ZS (Malvern Instruments Ltd).

\section{Preparation of urine, coated HAP crystals (cHAP), control (CS) and albumin solution (AS)}

15 spot urines were collected every morning freshly from one of 5 healthy men. $\mathrm{pH}$ was adapted to 6.0 , ionic sodium $\left(\mathrm{Na}^{+}\right)$measured and ionic calcium $\left(\mathrm{Ca}^{2+}\right)$ adapted to $2 \mathrm{mM}$. In one portion of this urine a crystallization test was performed without further pretreatment. In a second portion $0.05 \mathrm{mg} / \mathrm{mL}$ hydroxyapatite (HAP) crystals (SigmaAldrich Co., Germany) was incubated under continuous stirring. The other urine samples were always diluted to 50 or $33 \%$ with distilled water immediately before performing crystallization tests. After dilution $\mathrm{pH}$ was readapted to 6.0 and $\mathrm{Ca}^{2+}$ to $2 \mathrm{mM}$. CS was prepared in distilled water buffered with $5 \mathrm{mM}$ sodium cacodylate to $\mathrm{pH} 6.0$ and with concentrations of $100 \mathrm{mM} \mathrm{Na}^{+}$and $2 \mathrm{mM} \mathrm{Ca}^{2+}$. HAP-saturated CS (HCS) was obtained by incubation of CS with $10 \mathrm{mg} / \mathrm{mL}$ HAP during at least 1 week and centrifugation at a relative centrifugal force (rcf) of $2000 \mathrm{~g}$ for $10 \mathrm{~min}$. AS was freshly prepared for every experiment dissolving powdered human serum albumin (Sigma-Aldrich Co., Germany) in CS or HCS to a final albumin concentration of $20 \mu \mathrm{g} / \mathrm{mL}$. This concentration corresponds to a high physiological urinary excretion varying from 1.6 to $34 \mathrm{mg} /$ day [8]. Albumin-coated HAP crystals were prepared in HCS as mentioned above for urine.

\section{Preparation of dissolved Ca phosphate precipitates (DP) from urine and albumin solution}

$2 \mathrm{~mL}$ of urine or AS was titrated in the spectrophotometer under continuous stirring at $\mathrm{pH} 7.0$ by adding $0.5 \mathrm{mM} /$ min of a $100 \mathrm{mM} \mathrm{NaH} \mathrm{PO}_{4}$ solution. The critical phosphate addition for an increase of OD was determined and calculated in mM. In $20 \mathrm{~mL}$ of new urine or AS, respectively, after adaptation of $\mathrm{pH}$ to 7.0 a phosphate load was performed, exceeding the critical addition for precipitation by $1.0 \mathrm{mM}$. After $30 \mathrm{~min}$. of stirring, urine or AS was centrifuged and the supernatant discharged. The remaining sediment was dissolved in $20 \mathrm{~mL}$ of distilled water being buffered to $\mathrm{pH}$ 5.0. Complete dissolution was checked in the spectrophotometer. $\mathrm{pH}$ was adjusted to 6.0 and after measurement of $\mathrm{Ca}^{2+}$ and $\mathrm{Na}^{+}$these values were adapted to 2 or $100 \mathrm{mM}$, respectively. Particle size distribution was measured in AS and in DP prepared from AS.

\section{CaOx crystallization test}

$\mathrm{CaOx}$ crystallization was monitored by the spectrophotometer. Therefore, a quartz macro cuvette containing $2 \mathrm{~mL}$ of urine, CS or AS, respectively, was placed into the thermostattable cell holder of the spectrophotometer at $37{ }^{\circ} \mathrm{C}$. Under continuous stirring $0.3 \mathrm{mM} / \mathrm{min}$ sodium oxalate was added from a $80 \mathrm{mM}$ solution up to a final addition of $1.5 \mathrm{mM}$. At the end of the oxalate titration stirring was stopped and optical density (OD) was followed during further $25 \mathrm{~min}$ at $620 \mathrm{~nm}$ wavelength. To perform experiments with HAP, $2 \mathrm{~mL}$ of the $0.05 \mathrm{mg} / \mathrm{mL}$ HAP suspension in urine or HAPsaturated AS (HAS) was centrifuged (2000 $g$ for $10 \mathrm{~min}$ ), the supernatant discharged and the sediment resuspended in $2 \mathrm{~mL}$ of new urine or HAS, respectively.

\section{Evaluation of crystallization curves}

Characteristic crystallization curves are shown in Fig. 1. During Ox titration after a short period to reach the 


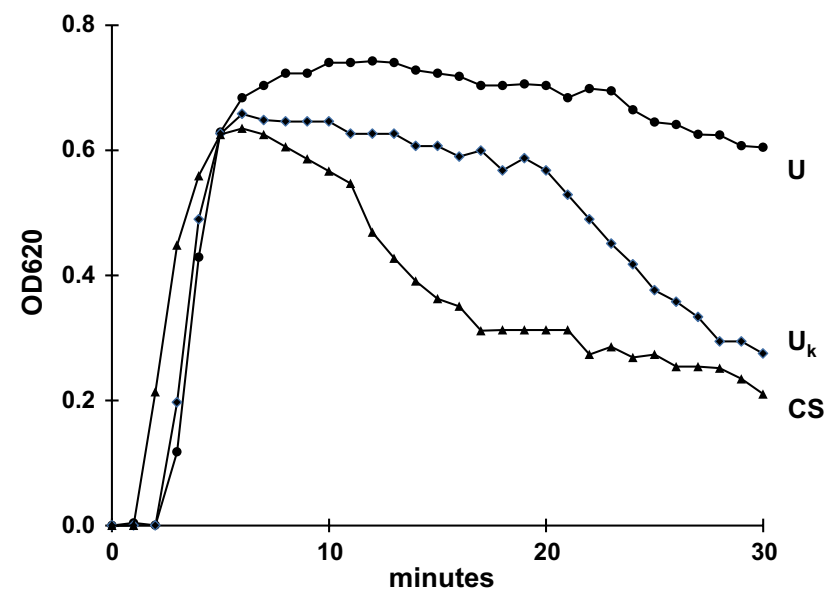

Fig. 1 Crystallization curves represented by optical density (OD) in urine without $(U)$, in urine with a kink in OD decrease $\left(U_{\mathrm{k}}\right)$ and in control solution (CS), the kink indicating AGN

metastable limit, OD steadily increases to a maximal value (mOD) being proportional to the crystal concentration in the suspension [12]. At the end of Ox titration and after stopping stirring, two different patterns of OD decrease are observed. One type where in the sediment by scanning microscopy only single crystals are found shows a slow and continuous OD decrease. The other type where large crystal aggregates in the sediment are present, after a short period of slow OD decrease is characterized by a sharp kink with a rapid OD drop [13]. For the evaluation of crystallization curves, $\mathrm{mOD}$ and the maximal rate of OD decrease $\left(\mathrm{mdOD} / \mathrm{dt}, \mathrm{min}^{-1}\right)$ were measured. OD decrease or the clearance of the particle suspension, respectively, occurs either when particles disappear by sedimentation out from the observation field of the spectrophotometer or when particle concentration or OD, respectively, is rapidly reduced by the association of many individual crystals in a few aggregates [10]. Results were indicated as mean \pm SD and probabilities were calculated by Mann-Whitney $U$ test.

\section{Results}

\section{Evaluation of crystallization curves observed in undiluted urine}

8 of 15 crystallization curves obtained in urine with coated HAP (cHAP) showed $10 \pm 4$ min after the stop of stirring a sharp kink of OD decrease indicating AGN. This kink as demonstrated in Fig. 1 also was found in CS. In 14 of 15 tests being performed without HAP only a slight and continuous OD decrease without a kink was observed.

Measurements of the crystallization parameters together with the initial urinary sodium concentration $\left(\mathrm{Na}^{+}\right)$are summarized in Table 1. Results are separately listed for urine samples without $(U)$ and with a kink $\left(U_{\mathrm{k}}\right)$ in the crystallization curve. The table shows that $\mathrm{Na}^{+}$was significantly higher in $U_{\mathrm{k}}$ than in $U$. The maximal OD reached after Ox titration (mOD) reflecting crystal concentration was generally higher in urine than in CS. The difference mainly can be attributed to the additional Ox brought with urine to the test system. A significantly elevated maximal rate of OD decrease (mdOD/ dt) indicating AGN was, as could be expected from the above-mentioned observation, exclusively found in experiments performed in $U_{k}$ containing cHAP. Values were in the range of those found in $\mathrm{CS}$, where the addition of HAP produced only a slight and non-significant further increase of mdOD/dt. Contrary to results obtained in CS almost all crystallization tests performed in urine without cHAP showed a low mdOD/dt indicating inhibition of AGN. cHAP at high $\mathrm{Na}^{+}$, the latter being an indicator for concentrated urine [14], seems to overwhelm this inhibition and promote $\mathrm{CaOx}$ AGN. For further investigation crystallization experiments were repeated after dilution of $U_{\mathrm{k}}$ samples.

\section{Effect of dilution}

Figure 2 shows the effect of the dilution of initially concentrated $U_{\mathrm{k}}$ on $\mathrm{mdOD} / \mathrm{dt}$. The figure demonstrates that
Table 1 Urinary sodium concentration $(\mathrm{Na}, \mathrm{mM})$, maximal optical density (mOD) and maximal rate of OD decrease ( $\mathrm{mdOD} / \mathrm{dt}, \mathrm{min}^{-1}$ ) in $U, U_{\mathrm{k}}$ and CS (for further details see Fig. 1)

\begin{tabular}{|c|c|c|c|c|}
\hline & $U$ & $U_{\mathrm{k}}$ & $\mathrm{CS}$ & $p$ \\
\hline $\mathrm{Na}^{+}$ & $67.9 \pm 22.6^{a)}$ & $125.3 \pm 17.2^{\mathrm{b})}$ & 100 & (a) vs (b) $<0.01$ \\
\hline $\mathrm{mOD}$ & $0.77 \pm 0.08^{\mathrm{a})}$ & $0.86 \pm 0.08^{\mathrm{b})}$ & $0.55 \pm 0.09^{\mathfrak{c})}$ & $\begin{array}{l}\text { (a) vs (c) }<0.01 \\
\text { (b) vs (c) }<0.01\end{array}$ \\
\hline $\mathrm{mOD}+$ & $0.73 \pm 0.08^{a)}$ & $0.77 \pm 0.18^{\mathrm{b})}$ & $0.43 \pm 0.05^{\mathrm{c})}$ & $\begin{array}{l}\text { (a) vs (c) }<0.01 \\
\text { (b) vs (c) }<0.05\end{array}$ \\
\hline $\mathrm{mdOD} / \mathrm{dt}$ & $0.008 \pm 0.002^{\mathrm{a})}$ & $0.011 \pm 0.004^{\mathrm{b})}$ & $0.033 \pm 0.008^{\mathrm{c})}$ & $\begin{array}{l}\text { (a) vs (c) }<0.01 \\
\text { (b) vs (c) }<0.01\end{array}$ \\
\hline $\mathrm{mdOD} / \mathrm{dt}+$ & $0.011 \pm 0.004^{\mathrm{a})}$ & $0.034 \pm 0.011^{\mathrm{b})}$ & $0.044 \pm 0.013^{\mathrm{c})}$ & $\begin{array}{l}\text { (a) vs (b) }<0.01 \\
\text { (a) vs (c) }<0.01\end{array}$ \\
\hline
\end{tabular}

Experiments performed in the presence of coated HAP are indicated by $(+)$. Results (mean \pm SD) are marked by $a, b$ and $c$ to indicate probability $(p)$ of differences 


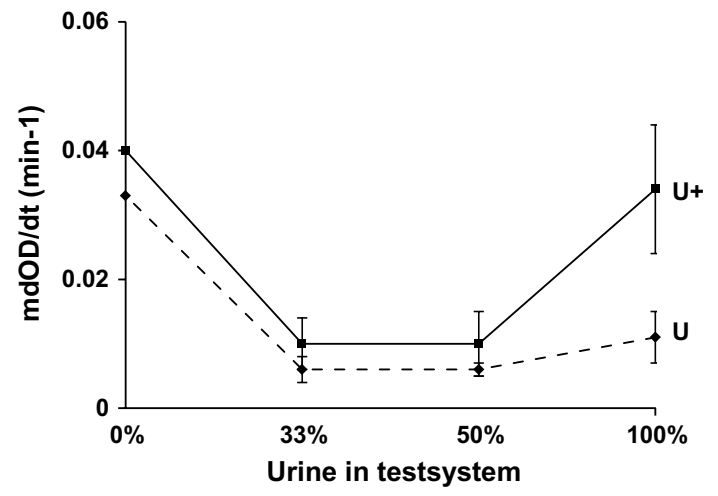

Fig. 2 Maximal rate of OD decrease (mdOD/dt, min-1) of $U_{k}$ with $(U+)$ and without coated HAP $(U)$ at different states of dilution indicated as percent of urine in the test system

dilution significantly $(p<0.01)$ reduced the elevated mdOD/dt observed in the concentrated $U_{\mathrm{k}}$ containing cHAP. The inhibition of AGN observed in tests performed without cHAP was not significantly changed even by an urine dilution down to $33 \%$. These experiments confirmed that a high urine concentration together with cHAP was responsible for $\mathrm{CaOx}$ AGN and furthermore showed that this cHAP-induced AGN could be prevented by urine dilution. Therefore, the question rises whether at high urinary concentration a weak promoter becomes active or inhibitory substances turn to promoters.

\section{Comparison of tests performed with $U_{\mathrm{k}}$ and albumin solution (AS) and with dissolved Ca phosphate precipitates (DP) from $U_{\mathrm{k}}$ and AS}

$U_{\mathrm{k}}$ and AS in high physiological concentration of $20 \mu \mathrm{g} / \mathrm{mL}$ showed, as Fig. 3 demonstrates, an almost identical behavior with respect to $\mathrm{mdOD} / \mathrm{dt}$. Both revealed without cHAP a very low $\mathrm{mdOD} / \mathrm{dt}$ indicating an excellent inhibition of AGN. Exposition of $U_{\mathrm{k}}$ and AS to pre-incubated HAP and the extract from $U_{\mathrm{k}}$ and AS in DP produced the same pronounced increase of mdOD/dt $(p<0.01)$. Albumin being the only crystallization modulator in the corresponding experiments changed, thus by adsorption on Ca phosphate, from an inhibitor to a promoter of $\mathrm{CaOx}$ AGN. Analysis of particle size distribution of AS showed apart from the main peak at $10 \mathrm{~nm}$ further smaller peaks of higher particle size, demonstrating some self-AGN. In DP, after temporary adsorption on Ca Phosphate, all albumin self-aggregated to a small single peak with a maximum at $470 \pm 14 \mathrm{~nm}$ (Fig. 4).

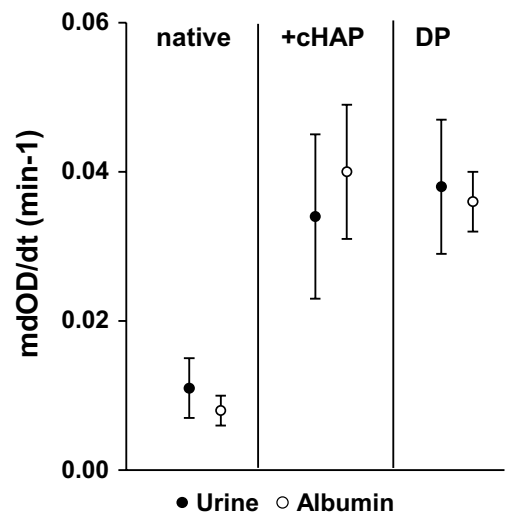

Fig. 3 Comparison of mdOD/dt observed in $U_{\mathrm{k}}$ and albumin solution (AS, $20 \mu \mathrm{g} / \mathrm{mL}$ ) without (native) and with coated HAP (+cHAP) and in the dissolved Ca phosphate precipitate (DP) from $U_{k}$ and AS

\section{Discussion}

This paper tries to give some answers to how urinary $\mathrm{CaOx}$ crystals especially in the presence of HAP can aggregate despite of their UM coat and how this AGN could be prevented. To induce spectrophotometrically measurable AGN within a time being similar to the generally short urinary transit time through the kidney, spot urine of healthy controls was rapidly titrated by a relative high dose of $1.5 \mathrm{mM}$ Ox. In a previous study performed after thawing of frozen urine, this Ox dose was able to induce $\mathrm{CaOx}$ AGN in 10 urine samples of 30 healthy controls and in 20 of 30 stone patients [10]. Interestingly, in the present study under almost identical conditions only in 1 of 15 freshly voided urine samples AGN was observed. These urines revealed thus a high inhibitory activity with respect to $\mathrm{CaOx}$ AGN which after freezing and thawing partially was lost. However, HAP crystals which previously were incubated in urine induced $\mathrm{CaOx}$ AGN in all urine samples with a relative high $\mathrm{Na}^{+}$. A high $\mathrm{Na}^{+}$as mentioned above is an indicator for concentrated urine. Dilution of urine abolished HAP-induced AGN but did not diminish the inhibitory activity with respect to pure $\mathrm{CaOx}$ crystallization even at urinary concentration in the test system of only $33 \%$. This agrees with the findings of others that urine of healthy subjects diluted to $20 \%$ strongly inhibited $\mathrm{CaOx}$ AGN [15]. Furthermore, a study of $\mathrm{CaOx}$ crystallization in urine of stone patients and controls under different states of diuresis revealed an inverse relationship between urine volume and the intensity of AGN [14]. The paradoxical fact that the dilution of urinary inhibitors prevented AGN was addressed but could not be explained by this study. 

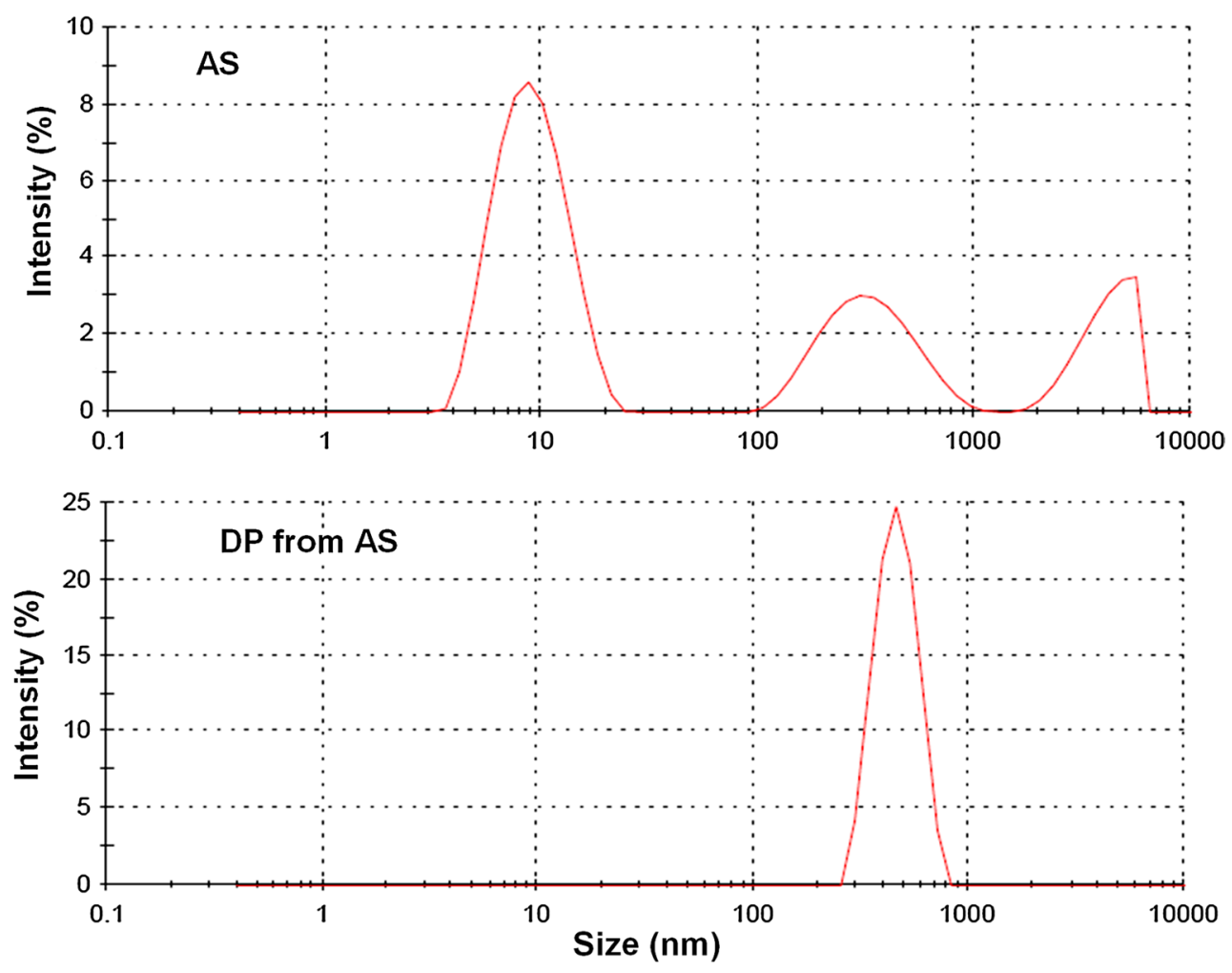

Fig. 4 Particle size distribution of AS and of DP from AS

AGN generally is ascribed to the attraction of particles by Van der Waal's forces (VWF) which are only effective at very short distances [16]. Other factors are viscous binding and solid bound formation. The first is a rapid process, the latter is slower as it requires deposition of further crystal material between already formed crystals. Particles like $\mathrm{CaOx}$ crystals have an electronegative surface charge which by electrostatic repulsion of the identically charged crystals normally prevents their AGN. By $\mathrm{Ca}$ addition to $\mathrm{CaOx}$ suspensions this surface charge was neutralized [17] and at sufficient crystal concentration, as demonstrated by our experiments performed in CS, crystals rapidly aggregated. In urine crystals normally are protected by a UM coat with a thickness of 10-20 nm [7] and with an electronegative potential in the order of $-15 \mathrm{mV}$ [13]. Such potentials are able to counteract VWF by repulsion of the identically charged particles [16]. However, as mentioned above, after high oxalate additions or at high crystal concentrations, respectively, $\mathrm{CaOx} \mathrm{AGN}$ also occurred in urine.

Three different theories try to explain the AGN of UMcoated particles: incomplete coating of crystals, insufficient surface potential of coats and bridging between crystals by altered proteins being called viscous binding [5]. Scanning microscopy of crystal aggregates being produced in protein solutions showed gaps in protein coats where some crystals were aggregated in direct contact with each other
[7]. But it could not be decided whether crystal coating had occurred before or after AGN and in other aggregates at points of crystal convergence large amorphous material was observed suggesting a bridging function of protein. The electronegative charge of UMs can be attributed to anionic residues like carboxyglutamic acid [18, 19], phosphate [20-22] and sialic acid [23, 24] which were found reduced in UMs of some stone patients. A lack of electrostatic repulsion is, therefore, often claimed to be responsible for AGN of urinary crystals. However, a reduction of anionic groups also enhances the hydrophobic effect in UMs which can provoke self-AGN. This was demonstrated by desialylation of Tamm Horsfall protein (THP) [24], an important UM involved in crystal adherence to RPs [2]. Normal THP in high concentration and at low $\mathrm{pH}$, high ionic strength and high $\mathrm{Ca}$ concentration too tend to self-AGN and promote $\mathrm{CaOx}$ AGN $[25,26]$. This promotion probably bases on a bridging function. In electrolyte containing solutions, surface potentials rapidly decrease with increasing distance from negatively charged particles by cation accumulation in their surroundings [16]. In urine with increasing concentration and ionic strength surface potentials are compressed to a few nanometers. Identically charged particles can, therefore, approach each other to a critical distance where diffusion, sedimentation or mechanic forces like stirring or shaking are compensated by the electrostatic repulsion. 
Large UM aggregates probably are able to bridge such zones of repulsion and to bind to crystal coats by hydrophobic effects [5].

The almost identical behavior of concentrated urine and albumin solution (AS) in our crystallization experiments showed that albumin is an ideal compound to mimic the overall effect of UMs under our special test conditions. In the presence of coated HAP (cHAP) the inhibition of $\mathrm{CaOx}$ AGN turned in both mediums to promotion. This effect was not directly related to cHAP since it was also observed in the dissolved Ca Phosphate precipitates (DP) of urine and AS. In this respect it is interesting to note that the formation of HAP in some loops of Henle with an urinary $\mathrm{pH}$ of 7.4 appears to be a normal phenomenon and that this HAP then dissolves in the distal part of the nephron where $\mathrm{pH}$ decreases [27]. Under these conditions the promoting effect of temporarily adsorbed UMs may persist and may favor the AGN of newely formed crystals in the distal nephron. A promoting effect on crystal AGN was also found in UMs isolated from urine by a hemofiltration procedure [11]. Crystal deposits as well as hemofilters provide a large surface for adsorption. Ca phosphate as demonstrated by the adsorption of 77 different proteins on brushite and of 45 on HAP [9] has a special ability for protein accumulation which may explain the essential role of HAP containing Randall's plaques (RPs) in idiopathic $\mathrm{Ca}$ nephrolithiasis [2]. With respect to albumin it could be demonstrated that adsorption on $\mathrm{Ca}$ phosphate produced albumin aggregates with an average diameter of $470 \mathrm{~nm}$ largely being able to take over a bridging function. However, in our study such a bridging probably was counteracted by urine dilution which by diminishing ionic strength increases the radius of electrostatic repulsion and thus the distance between crystals to be bridged for AGN. On the other hand, our experiments performed with cHAP suggests that at a critical urinary concentration RPs and intratubular crystal deposits being coated by aggregated UMs are ideal platforms for stone growth by crystal AGN during crystalluria. Scanning electron microscopy of urinary sediments performed after HAP-induced $\mathrm{CaOx}$ AGN showed in agreement with findings on RPs large $\mathrm{CaOx}$ aggregates which were in the surroundings of HAP but not in direct contact with HAP crystals [28]. HAP thus seems not to act as nucleator of $\mathrm{CaOx}$ crystallization in urine but as mediator for the self-AGN of UMs which promote crystal AGN.

\section{Conclusions}

Our findings give further evidence that $\mathrm{CaOx}$ AGN in urine probably is mediated by self-aggregated UMs forming bridges between UM-coated crystals. Whether pathological UMs or as our study suggests a pathological urine concentration is more relevant for $\mathrm{CaOx}$ AGN cannot be decided. However, the observation that crystal AGN is enhanced by a high urine concentration is a further argument in stone metaphylaxis to increase diuresis as being already established to diminish urinary supersaturation as well as urinary transit time in the renal collecting system. The influence of freezing and hemofiltration on results of crystallization experiments demonstrates that tests performed in freshly voided and unpretreated urine are important for the study of inhibitors and promoters in stone research.

Acknowledgments We thank Dres. Harry Borer, Hans Peter Siegrist and Edouard Viollier who have sponsored our stone research during more than 30 years.

\section{Compliance with ethical standards}

Ethical standards All studies have been approved by the appropriate ethics committee and have, therefore, been performed in accordance with the ethical standards laid down in the 1964 Declaration of Helsinki and its later amendments. All persons gave their informed consent prior to their inclusion in the study.

Conflict of interest The authors declare that they have no conflict of interest.

Open Access This article is distributed under the terms of the Creative Commons Attribution 4.0 International License (http://creativecommons.org/licenses/by/4.0/), which permits unrestricted use, distribution, and reproduction in any medium, provided you give appropriate credit to the original author(s) and the source, provide a link to the Creative Commons license, and indicate if changes were made.

\section{References}

1. Daudon M, Bazin D, Letavernier E (2015) Randall's plaque as the origin of calcium oxalate kidney stones. Urolithiasis 43(Suppl 1):5-11. doi:10.1007/s00240-014-0703-y

2. Evan AP, Worcester EM, Coe FL, Williams J Jr, Lingemann JE (2015) Mechanisms of human kidney stone formation. Urolithiasis 43(Suppl 1):19-32. doi:10.1007/s00240-014-0701-0

3. Robertson WG (2015) Potential role of fluctuations in the composition of renal tubular fluid through the nephron in the initiation of Randall's plugs and calcium oxalate crystalluria in a computer model of renal function. Urolithiasis 43(Suppl 1):93-107. doi:10.1007/s00240-014-0737-1

4. Khan SR, Canales BK (2015) Unified theory on the pathogenesis of Randall's plaques and plugs. Urolithiasis 43(Suppl 1):109123. doi:10.1007/s00240-014-0705-9

5. Baumann JM, Affolter B (2014) From crystalluria to kidney stones, some physicochemical aspects of calcium nephrolithiasis. World J Nephrol 3(4):256-267. doi:10.5527/wjn.v3.i4.256

6. Saw NK, Rao PN, Kavanagh JP (2008) A nidus, crystalluria and aggregation: key ingredients for stone enlargement. Urol Res 36(1):11-15

7. Khan SR, Finlayson B, Hackett RL (1983) Stone matrix as proteins adsorbed on crystal surfaces: a microscopic study. Scan Electron Microsc 379-85. doi:10.1007/s00240-013-0604-5

8. Khan SR, Kok DJ (2004) Modulators of urinary stone formation. Front Biosci 9:1450-1482 
9. Thurgood LA, Ryall RL (2010) Proteomic analysis of proteins selectively associated with hydroxyapatite, brushite, and uric acid crystals precipitated from human urine. J Proteome Res 9(10):5402-5412. doi:10.1021/pr1006312

10. Baumann JM, Affolter B, Casella R (2011) Aggregation of freshly precipitated calcium oxalate crystals in urine of calcium stone patients and controls. Urol Res 6:421-427. doi:10.1007/ s00240-011-0382-x

11. Baumann JM, Affolter B, von Arx U, Noël M (2013) Alteration of urinary macromolecules by adsorption on surfaces, probably an important factor in urolithiasis. Urolithiasis 41(6):467-474. doi:10.1007/s00240-013-0604-5

12. Hess B, Nakagawa Y, Coe FL (1989) Inhibition of calcium oxalate monohydrate crystal aggregation by urine proteins. Am J Physiol (Renal Fluid Electrol Physiol 26) 257:99-106

13. Baumann JM, Affolter B, Caprez U, Clivaz C, Glück Z, Weber R (2007) Stabilization of calcium oxalate suspension by urinary macromolecules, probably an efficient protection from stone formation. Urol Int 79:267-272

14. Guerra A, Allegri F, Meschi T, Adorni G, Prati B, Nouvenne A, Novarini A, Maggiore U, Fiaccadori E, Borghi L (2005) Effects of urine dilution on quantity, size and aggregation of calcium oxalate crystals induced in vitro by an oxalate load. ClinChem Lab Med 43:585-589

15. Kok DJ, Papapoulos SE, Bijvoet OL (1990) Crystal agglomeration is a major element in calcium oxalate urinary stone formation. Kidney Int 37:51-56

16. Müller RH (1996) Zetapotential und Partikelladung in der Laborpraxis. Wissenschaftliche Verlagsgesellschaft, Stuttgart, p 37

17. Baumann JM, Affolter B, Caprez U, Clivaz C, von Arx U (2009) Role of calcium in the aggregation of particles coated by urinary macromolecules. Urol Int 82:459-463

18. Cook AF, Grover PK, Ryall RL (2009) Face-specific binding of prothrombin fragment 1 and human serum albumin to inorganic and urinary calcium oxalate monohydrate crystals. BJU Int 103(6):826-835
19. Coe FL, Nakagawa Y, Asplin J, Parks JH (1994) Role of nephrocalcin in inhibition of calcium oxalate crystallization and nephrolithiasis. Miner Electrolyte Metab 20(6):378-384

20. Kolbach AM, Afzal O, Halligan B, Sorokina E, Kleinman JG, Wesson JA (2012) Relative deficiency of acidic isoforms of osteopontin from stone former urine. Urol Res 40(5):447-454

21. Grohe B, Chan BP, Sørensen ES, Lajoie G, Goldberg HA, Hunter GK (2011) Cooperation of phosphates and carboxylates controls calcium oxalate crystallization in ultrafiltered urine. Urol Res 39(5):327-338

22. Wang L, Guan X, Tang R, Hoyer JR, Wierzbicki A, De Yoreo JJ, Nancollas GH (2008) Phosphorylation of osteopontin is required for inhibition of calcium oxalate crystallization. J Phys Chem B 112(30):9151-9157

23. Webber D, Radcliff CM, Royle L, Tobiasen G, Merry AH, Rodgers AL, Sturrock ED, Wormald MR, Harvey DJ, Dwek RA, Rudd PM (2006) Sialylation of urinary prothrombin fragment 1 is implicated as a contributory factor in the risk of calcium oxalate kidney stone formation. FEBS J 273(13):3024-3037

24. Viswanathan P, Rimer JD, Kolbach AM, Ward MD, Kleinman JG, Wesson JA (2011) Calcium oxalate monohydrate aggregation induced by aggregation of desialylated Tamm-Horsfall protein. Urol Res 39(4):269-282

25. Jaggi M, Nakagawa Y, Zipperle L, Hess B (2007) Tamm-Horsfall protein in recurrent calcium kidney stone formers with positive family history: abnormalities in urinary excretion, molecular structure and function. Urol Res 35:55-62

26. Scurr DS, Robertson WG (1986) Modifiers of calcium oxalate crystallization found in urine. III. Studies on the role of TammHorsfall mucoprotein and of ionic strength. J Urol 136:505-507

27. Kok DJ (1997) Intratubular crystallization events. World J Urol 15:219-228

28. Baumann JM, Affolter B, Caprez U, Henze U, Lauper D, Maier F (2001) Hydroxyapatite induction and secondary aggregation of calcium oxalate, two important processes in calcium stone formation. Urol Res 29:417-422 